Article

\title{
Electric Mobility and Smart Mobility Concepts-Restrained Uptake in German Cities
}

\author{
Doris Johnsen ${ }^{1, *}$, Frederik Vorholt ${ }^{2, *}$, Jan-Hinrich Gieschen ${ }^{1}$, Beate Müller ${ }^{3}$ and \\ Annette Randhahn ${ }^{3}$ \\ 1 Institute for Innovation and Technology (iit) in the VDI/VDE Innovation + Technik GmbH, Steinplatz 1, \\ 10623 Berlin, Germany; gieschen@iit-berlin.de \\ 2 TÜV Rheinland Consulting GmbH, Am Grauen Stein, 51105 Cologne, Germany \\ 3 VDI/VDE Innovation + Technik GmbH, Steinplatz 1, 10623 Berlin, Germany; \\ beate.mueller@vdivde-it.de (B.M.); annette.randhahn@vdivde-it.de (A.R.) \\ * Correspondence: johnsen@iit-berlin.de (D.J.); frederik.vorholt@de.tuv.com (F.V.); \\ Tel.: +49-(0)30-310078-5582 (D.J.); +49-(0)30-756-874-160 (F.V.)
}

Received: 18 October 2019; Accepted: 8 November 2019; Published: 19 November 2019 updates

\begin{abstract}
Ninety German cities exceeded the European threshold on $\mathrm{NO}_{2}$ in 2016, 65 of those cities developed countermeasures and strategies that were published in Green City Plans (GCP). In the scope of this study, 55 publicly available GCPs were evaluated in order to assess their potential for traffic turnaround at a municipal level. All GCPs were analyzed to determine in which of the mentioned five to seven fields of action the respective city had planned measures and which fields of action were prioritized. A more in-depth qualitative analysis of the main topics: Electric mobility, public transport, and mobility concepts was carried out. To get a better understanding of the potential impact of the measures elaborated in the GCPs, complementary information on municipal fleet vehicle stocks, requirements of charging infrastructure for public buses and results of the European roadmap on mobility concepts are given. The evaluation of the GCPs showed that to this day, city administrations mainly optimize the current system by measures of electrification and digitization. Electrification of municipal fleets, car-sharing fleets, and public transport buses is in the focus of the strategies. Instruments to increase non-motorised transport, sustainable commercial transport, and/or mobility concepts are mentioned, but play a minor role. However, there still has been no system change in Germany. Therefore, a substantial turnaround of the transport system ("Verkehrswende") is necessary. This applies to integrated urban and transport planning, flexible, strong, fast PT, non-motorised and flexible operating systems.
\end{abstract}

Keywords: mobility system; mobility concepts; EV (electric vehicle), municipal government; sustainability; green city master plan; transport system; climate mitigation

\section{Introduction: Transport and Climate Policies}

\subsection{From Paris to German Municipalities}

This article evaluates the Green City Plans (GCP) of German municipalities. It also explains the activities on the local level in Germany to mitigate climate change and to affect a mobility turnaround. The results of this evaluation were presented at a poster session during the EVS32 in Lyon in 2019 [1].

With the international climate protection agreement in Paris in 2015, all signing countries agreed on a voluntary commitment to limit global warming to 1.5 degrees Celsius. The European Union (EU) committed to reducing greenhouse gas emissions by $40 \%$ until 2030 (compared to 1990). In 2008, the European member states agreed on the increase of the share of renewable energies up to $20 \%$ of the total energy use (electricity, transport, heating, and cooling) in the EU climate and energy pact 2020 [2]. 
In Germany, the transport sector accounts for almost $18 \%$ of the total greenhouse gas emissions. Thus, transport is the third largest producer of emissions in Germany. Moreover, $96 \%$ of the emissions from the transport sector result from road traffic [2].

Besides that, the annual survey of the European Environment Agency shows that, compared to other European countries, an above-average number of cities in Germany exceed the $\mathrm{NO}_{2}$ limits of $40 \mu \mathrm{g} / \mathrm{m}^{3}$, as shown in Figure 1 [3]. This underlines the immediate need for action Germany has to comply with on the local level in order to achieve the required emission reduction.

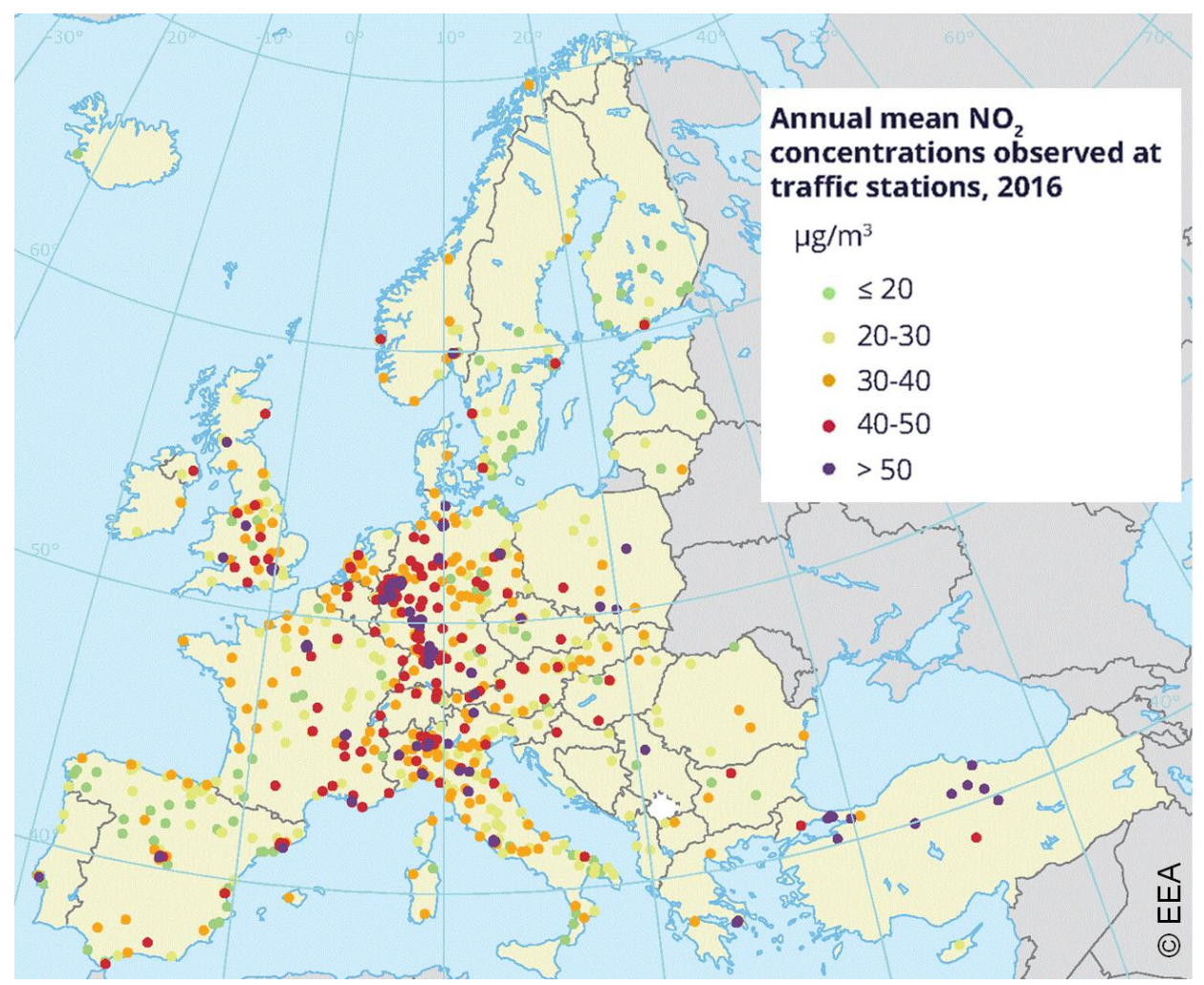

Figure 1. Annual mean $\mathrm{NO}_{2}$ concentration observed at traffic stations, 2016 [3] (The original Source of this map is the EEA. The original meaning and message of the content of this map is not distorted).

The German Federal Government has clear targets for climate protection and related issues, such as electric mobility and energy efficiency. These overarching objectives must be subdivided into operational tasks that are implemented at the local level. Due to the high sovereignty of municipal administration, the federal policy can only exert limited influence on how the overarching goals are implemented locally. At the same time, there may be conflicts of interest between the federal level and local policies. For example, the Electric Mobility Act, which came into force in summer 2015, offers local authorities the opportunity to favor electric vehicles, e.g., by allowing them to use bus lanes. On the other hand, it is favorable for local authorities to give preference to public transport and to restrict motorized private transport. It is, therefore, unlikely that all instruments provided in this Federal Act will be implemented on a municipal level $[4,5]$.

The Federal Government and the Federal States also affect local activities by tendering funding for procurement as well as research and development. On the other hand, the institution KOINNO, which supports public bodies in introducing innovative procurement instruments, states that new technologies and innovative products are rarely used by public entities in Germany [6]. This is confirmed by the fact that only every second municipality feels prepared for the challenges of digitization [7]. On the other hand, more than half of the municipalities see the urgent need to implement new mobility concepts [8]. Electromobility plays a key role here. As a recent survey of 540 German municipalities 
with 5000 inhabitants or more shows, electric mobility is of great importance to two-thirds of the municipalities [9].

\subsection{Challenges in the Transport Sector}

However, transport does not only stand for emissions that have to be reduced in line with climate protection targets. Mobility is one of the basic prerequisites for the functioning of urban areas. At the same time, transport and urban infrastructure determine to a great extent future developments. For example, in the years 1950-1960 car-oriented urban planning dominated in German and other European cities. Urban planning separated traffic modes and functionality of city districts, led to the construction of large traffic axes, and gave priority to individual motorized transport. Nowadays, the cities have to cope with that legacy. For this reason, the German Federal Government has established a transformation process within the framework of climate policy under the term "Verkehrswende", which follows amongst others the principles of avoiding, relocating and improving efficiency in the transport sector [10].

In principle, transport has likewise negative impacts on the quality of life in cities, such as pollution, traffic, congestion, long time to cross the city (negative impact on work and life balance), high cost of public local transport services, etc. [11]. Achieving a sustainable, inclusive and efficient mobility system for people and goods is the overall challenge to be dealt with in the Smart Mobility action field [12]. With the development of new technological innovations (in particular ICT), the concept of the Smart City was seen as a means of achieving more efficient and sustainable cities. In these concepts, Smart Mobility is one of the most promising topics, as it could produce high benefits for the quality of life for almost all city stakeholders [11]. Taken all together, transport planning must be integrated into overall urban planning that takes into account all behavioral aspects of mobility, which determine the sum of all personal choices about means of transport, place of residence, etc. and needs to pay attention to all modes equally.

The Sustainable Cities Mobility Index by Arcadis provides an approach to quantify the state of a city's urban mobility environment considering all different requirements [13]. It takes into account the social and human implications of mobility systems, including quality of life (People), "green" factors such as energy, pollution, and emissions (Planet) as well as the efficiency and reliability of a mobility system to promote economic growth (Profit). The indicators of this index show the wide variety of determinants a sustainable mobility planning needs to take into account and cover several relevant criteria to determine the modal choice. According to Arcadis, an effective transport system can simultaneously address and improve its functioning for all stakeholders, while facilitating economic opportunities without compromising environmental concerns. To achieve a high index value, each of the sub-indices People, Planet and Profit must be strong. In the ranking of the 100 world's leading cities, seven European cities are among the top ten, including one German city. A differentiated view shows that there are no German cities to be found in the top ten of the sub-indices People and Profit. However, German cities occupy the top three places in the top ten of the sub-index Planet that includes indicators such as $\mathrm{CO}_{2}$ emissions, air pollution, congestions, and efforts to lower emissions, bicycle infrastructure, electric vehicle incentives and provision of green space. In total, however, only four German cities are among the top one hundred cities. This creates a need for further measures to transfer the good approaches to green factors to other cities, while significantly improving the pillars People and Profit. The first means improving indicators such as road safety, access to transport services, modal split, digitization of the transport system, and PT duty time. The second means that factors such as efficiency and reliability of a mobility system, in particular in terms of commuting time, traffic revenue in relation to the total cost and affordability of PT, need to be improved. For improvement of transport in all areas, i.e., in the three indices of Arcardis, People, Planet and Profit, German municipalities and cities must be empowered to locally expedite smart services as well as smart mobility concepts. This requires, amongst others, gaining confidence in working with innovative procurement instruments for public authorities [6]. 
Transport is one of the main sectors responsible for greenhouse gas emissions (GHG) in Europe. Electric mobility has a high potential to reduce harmful emissions [14]. However, the positive effects of electrifying car fleets differ greatly between countries [15]. This is because the environmental benefits of electric mobility are highly depending on the electricity mix of the country. Moro and Lonza indicate the potential of greenhouse gas emission reduction of electric vehicles instead of gasoline vehicles to be at about $60 \%$ [16]. Biresselioğlu et al. identified main barriers for the uptake of electric mobility: Lack of charging infrastructure, economic, technical, and operational restrictions, costs as well as lack of trust, information and knowledge-limited supply of electricity and raw material. Key motivators are environmental, economic, and technical benefits, personal, and demographic factors [14]. Plötz et al. identified that income, gasoline prices, direct and indirect subsidies have a positive impact on the uptake of PEV [17]. Electric mobility is also one of the focus areas of transport policy in Germany. A broad portfolio of policy measures and regulations has been introduced, such as the electric mobility act, a purchase subsidy ("Umweltbonus") for electric vehicles (BEV and PHEV), tax incentives, public subsidies, and investments in charging infrastructure. With regard to charging infrastructure, Harrison and Thiel stated that there is an important interaction between different powertrain types and the provision of filling infrastructure. Nevertheless, in the early market stages, the correlation would be weaker than other policy measures. For example, the provision of more than one charging point for one strong plug-in electric vehicle (PiEV) would lead to a small gain, but also to high costs [18].

\section{Materials and Methods}

\subsection{Materials: Green City Plans, Germany}

In 2016, ninety German cities exceeded the permissible annual EU threshold of nitrogen oxides $\left(\mathrm{NO}_{2}\right)$. Since $\mathrm{NO}_{2}$ is mainly produced during combustion processes in plants and engines, transport accounts for a very large share. According to this, the EU Commission sued Germany, as well as five other member states, for air pollution in 2018 and the Deutsche Umwelthilfe has filed lawsuits against numerous cities for persistently high levels of $\mathrm{NO}_{2}$ in the air. As a result, driving bans for emission-intensive diesel vehicles have been imposed by courts in the recent past, e.g., in Hamburg and Stuttgart.

In 2017, the Federal Government launched the "Immediate Action Programme for Clean Air". The objective is to achieve rapid and sustained improvement of air quality in those towns and cities where the annual average air quality threshold for $\mathrm{NO}_{2}$ is exceeded. The prerequisites for receiving specific funding from the Action Programme are so-called Green City Plans (GCPs). The aim of these GCPs is to help local authorities address the issue of sustainable urban mobility in a long-term and strategic way. These comprehensive strategic concepts should show how the concerned municipalities intend to reduce nitrogen oxide pollution in the short, medium, and long-term and how to shape sustainable mobility in their regions in the future [19].

Accordingly, the GCPs contain the concepts and ideas of German cities and municipalities on how their local transport systems will address and improve its functioning for all stakeholders simultaneously in the future while facilitating economic opportunities without compromising environmental concerns. In order to find out which measures are being taken or planned by the cities most affected by high $\mathrm{NO}_{2}$ emissions, all 55 publicly accessible GCPs were evaluated.

In addition, the electrification of municipal vehicle fleets and public transport was weighed. Publicly available data provided by the German Federal Motor Transport Authority were used to identify the amount of electrified municipal fleet vehicles in Germany. Information on the general conditions for charging electric buses and a good practice example showing the challenges in charging buses in bus depots were provided by scientific articles and grey literature. This information is given in Section 3.2 Electrification of municipal fleets in German cities and Section 3.4 Charging Infrastructure for Battery Electric Buses, respectively. 
Results of the EU project Mobility4EU were used to compare the mobility concepts mentioned in the GCPs with ideas and requirements, user needs etc. that were worked out in a roadmap process within this project.

\subsection{Methods}

The method applied to evaluate the GCPs was chosen as follows: First, the specific problem situation of each city was identified and the various fields of action were gathered. It turned out that there are seven fields of action to which almost all measures can be assigned: Traffic management/digitization, public transport (PT), electric mobility, cycling, urban logistics, mobility services, and autonomous driving. Thereby, the first five topics were expected to be dealt with if the municipalities received funds from the Federal Ministry of Transport for the preparation of the GCPs. Secondly, all GCPs were analyzed to determine in which of the seven fields of action the respective city had planned measures and which fields of action were prioritized. Prioritization would have been undertaken, e.g., by assessment of the measures or emphasizing in the text. Finally, a more in-depth qualitative analysis of the main topics: Electric mobility, public transport, mobility concepts as well as analysis related to city size was carried out.

To get a better understanding of the potential impact of the measures elaborated in the GCPs, the above-mentioned complimentary references were considered. Complementary information on municipal fleet vehicle stocks, requirements of charging infrastructure for public buses and results of the European roadmap on mobility concepts are given as such. They show scales, requirements, and frameworks regarding the specific action fields and offer an orientation for discussions.

\section{Results: German Cities Focus in GCPs Mainly on Same Action Fields}

The evaluation of all GCPs shows that more than $80 \%$ of the cities envisage measures in the fields of action: Traffic management, electric mobility, cycling, and public transport. In just under $80 \%$ of all GCPs, measures in the area of urban logistics are mentioned. Measures concerning mobility services are mentioned in almost $70 \%$ of the plans. Approximately every fifth plan mentions measures in the field of autonomous driving. Figure 2 shows the occurrences of measures in the seven action fields that were identified by analyzing 55 GCPs. In the figure, the occurrences are shown differentiated according to prioritized naming, simple naming, or not named.

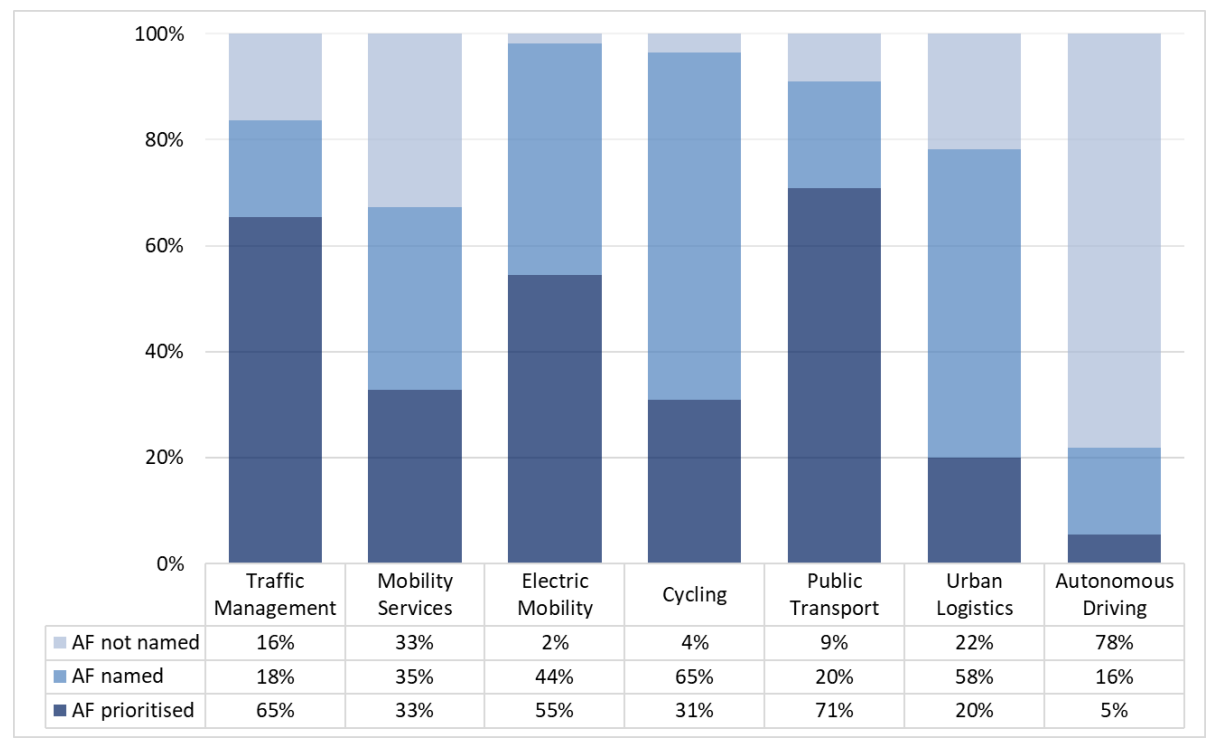

Figure 2. Seven identified action fields (AF) and the occurrences of measures in these action fields. A differentiation is made as to whether measures are prioritized, mentioned at all or not mentioned. Total number of analyzed Green City Plans: 55. 
In $18 \%$ of all GCPs measures in the action field traffic management are mentioned, whereas in $65 \%$ of all plans those measures are prioritized. Parking guidance systems, as well as intelligent traffic lights and traffic management systems for improving the flow of traffic, are the most commonly named actions. Measures in the action field mobility services are mentioned in $35 \%$ of all GCPs and prioritized in a further third of all plans. The spectrum ranges from need-based ride-sharing systems, which supplement public transport in off-peak times, to multimodal hubs, which are intended to connect all modes of transport. Almost every master plan mentions measures relating to the electrification of modes of transport, the action field electric mobility. In just over half of them (55\%), measures in this field of action are prioritized. The focus is on the electrification of bus fleets and/or municipal vehicle fleets as well as the expansion of charging infrastructure. Almost every master plan mentions measures in the action field cycling. However, in less than one-third of all plans, those measures are prioritized. In nearly all cases, the focus is on improving the basic conditions for cycling, such as the overhaul and/or expansion of cycle paths. In $20 \%$ of all GCPs measures in the action field public transport are mentioned, whereas those measures are prioritised in $71 \%$ of all plans. The focus is on the conversion of diesel buses to low-emission or locally emission-free drives as well as on upgrading the infrastructure and expanding the offering. Measures in the action field urban logistics are mentioned in $58 \%$ of all GCPs. In $20 \%$ of all plans, corresponding measures are prioritized. These are mostly measures for the flexible and environment-friendly design of inner-city distribution traffic, e.g., last-mile logistics. In $16 \%$ of all GCPs measures in the action field autonomous driving are mentioned, whereas in $5 \%$ of all plans those measures are prioritized. In this field of action, approaches for autonomous shuttles are listed, primarily intended to supplement public transport.

In the following part, the results of the qualitative analysis of the action fields electric mobility, public transport, and mobility concepts are presented, as these topics are three of the most important focus areas to achieve a switch to sustainable urban transport and mobility. To emphasize the significance of the action fields, some of them are discussed further by complementing the results of the GCP-analysis with independent research on the same topic.

\subsection{Focus on Fleet Electrification and Infrastructure Provision-A Closer Look on the Action Field Electric Mobility in the GCPS}

As shown in Figure 3, almost all GCPs include the promotion of electric mobility as a locally emission-free alternative to vehicles powered by a combustion engine. It can clearly be seen that cities with 250-500 k inhabitants prioritize this action field most often.

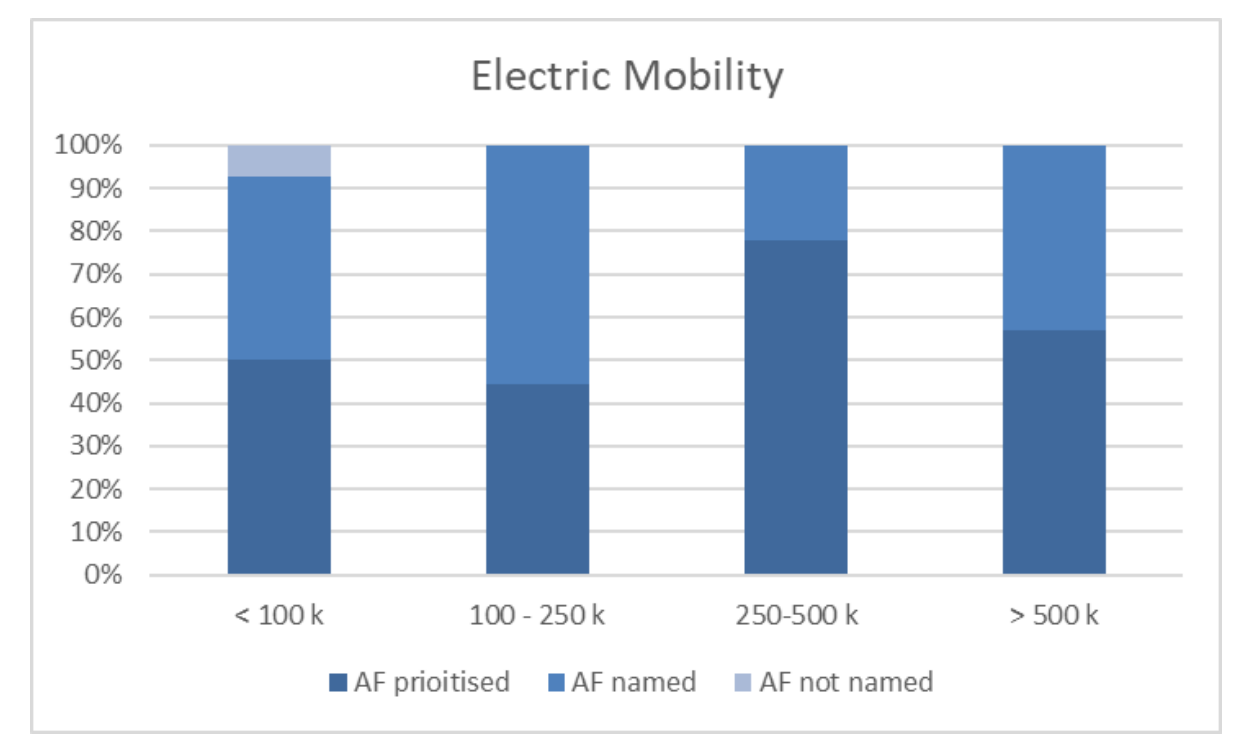

Figure 3. Action field (AF) electric mobility. A differentiation is made as to whether measures are prioritized, mentioned at all or not mentioned. Total number of analyzed Green City Plans: 55. 
In the GCPs, most often the electrification of either local buses or municipal fleets or both is stated. The most important measures mentioned are the electrification of vehicles and building up infrastructure, in particular charging infrastructure (including low-cost charging infrastructure). Many cities map out to electrify their bus fleets, some cities plan to shift fuels from diesel, e.g., to gas or hydrogen. Likewise, many cities start the electrification of their municipal fleets.

Some cities, among them Freiburg, address the electrification of local sharing, ride-hailing, and cab fleets (e.g., CleverShuttle, traditional station-based or free-floating car sharing) and two-wheelers. The city of Hamburg stands out by the integrated approach to include electric mobility directly while planning district developments. Wiesbaden states that the city wants to develop as a pilot and showcase city for electric mobility. As a kind of casual manner, the city of Essen plans to establish counseling centers for electric mobility.

\subsection{Electrification of Municipal Fleets in German Cities}

It is often stated that the electrification of municipal fleets is of great relevance for promoting the development of electric mobility in a country. For example, it is expected that scale effects on the production of electric vehicles can occur by the procurement of greater fleets. In addition, if greater fleets are electrified, the usage of charging infrastructure will increase, which makes it more economically feasible for providers, and therefore, more interesting to build up more infrastructure. However, an important question in this context is the effect of public support, especially public funding, for the electrification of municipal fleets.

The funding of municipal fleets has some kind of "tradition" in Germany, ever since the Showcase Electric Mobility Programme of the Federal Government (with the participation of four Federal Ministries) and the Electric Mobility Model Regions of the Federal Ministry of Transport, Building and Urban Affairs, in both of which electrification of municipal fleets played an important part.

However, to this day, there is no clear evidence, whether the funding of the electrification of municipal fleets has clear effects on the growth of electric mobility.

It is not easy to give a better understanding of the potential scale, as it is difficult to obtain reliable data on municipal fleets, since they are not captured by official statistics. There are mainly two reasons for this problem. In Germany, the only available data can be taken from the vehicle registration office. During the registration, one has to inform on vehicle ownership, but it is only differentiated between private and commercial ownership. Concerning commercial ownership, one also has to provide information on the sector of the economy. Therefore, municipal vehicles are classified as commercial vehicles. Furthermore, it depends on the definition of municipal fleets, what is being considered a "municipal vehicle" [20]. Is it a fleet of vehicles which is actually owned by a municipality (e.g., cars from the office of public order) or vehicles which fulfill an important function for the municipality (e.g., care services), but can also be owned by private companies? As mentioned before, there is no "official" definition. However, if you take a closer look at the funding conditions of the relevant programs, they are often focused on the latter aspect.

Important areas of use of vehicles under municipal contracts are initially the respective own fleet of the municipality and public administration (e.g., for business trips). In addition, vehicles can be used on a municipal or community basis, such as municipal utilities (e.g., for energy or waste disposal) and public transport. Municipal vehicles could also be used in other municipal companies, such as municipal housing companies.

Based on these assumptions, it is possible to evaluate the systematics of the German Federal Motor Transport Authority (Kraftfahrtbundesamt, KBA) in order to make a first assessment of municipal fleets. The estimation is based on qualitative characteristics and the following activities or sectors of the economy are included:

- Power supply

- Water supply, sewage and waste disposal, and pollution remediation

- Transportation and storage 
- Real estate and housing

- Provision of other services

- Public administration

- Health and social work

Hereinafter, these are summed up and called municipal fleets. However, according to the situation mentioned before, the overview does not claim to be complete. For example, car sharing services are not considered here. Figure 4 shows the results of this evaluation based on data by the German Federal Motor Transport Authority (KBA). The figure shows the stock of the electrical municipal fleets as well as the share of electrical municipal fleets of the total municipal fleet (all drive types).

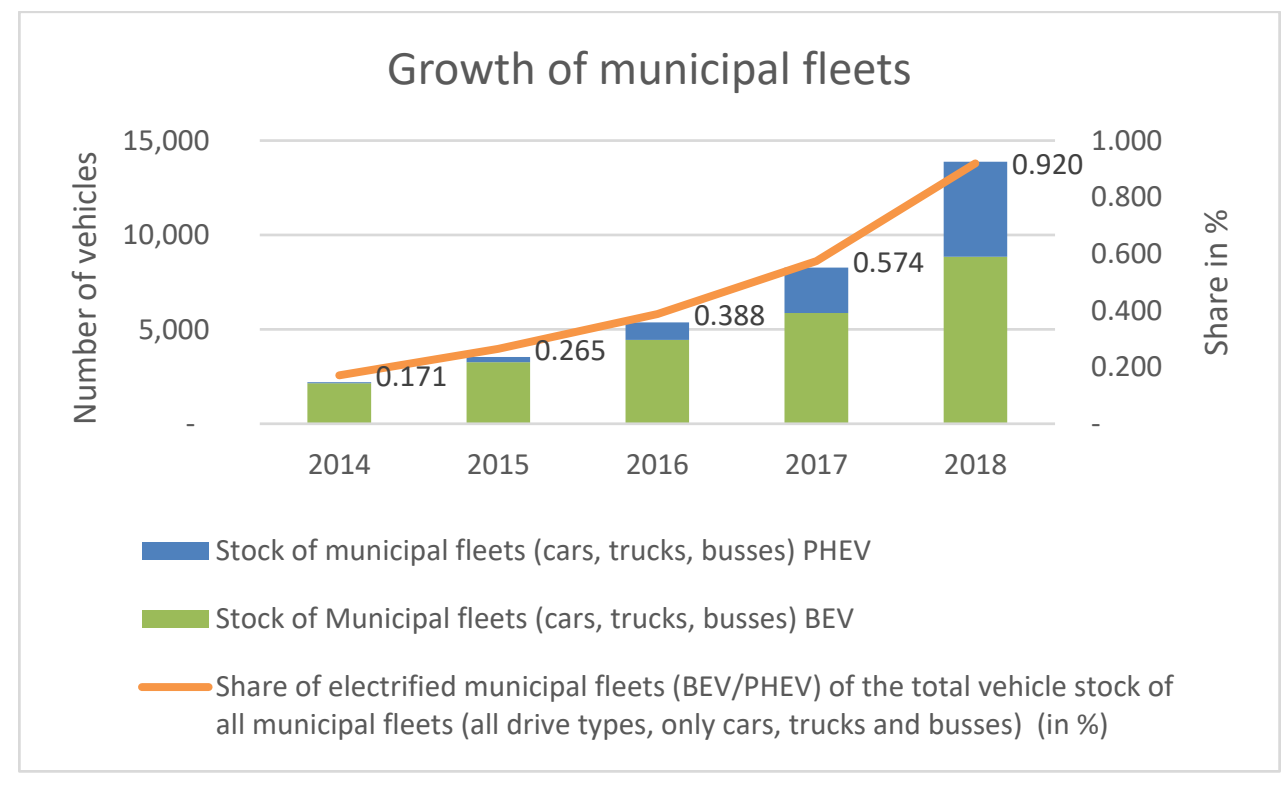

Figure 4. Growth of electrified municipal fleets. Due to data availability, total vehicle stock of all municipal fleets includes some data (e.g., logistics) which are not taken into account in data for electrified fleets. This might result in small distortions. (Source: own diagram; Data Source: [21], the year given is the year of reporting).

Although the stock of the electric municipal fleet, as well as the share of the electric municipal fleets, in Germany has grown over the years, it can be seen that both are still at a very low level. In 2018, the share of electric vehicles of all municipal cars is still below $1 \%$, the stock of electric vehicles (cars, trucks, buses) counts only 13,878 vehicles (compared to approx. 1,500,000 vehicles of all drive types in municipal fleets, Figure 4).

More differences can be seen if the shares of the municipal fleet, electric and all drive types are compared to the total stock of vehicles in Germany (Figure 5). Although the stock of municipal fleets compared to all drive types is also quite low at $3 \%$ in 2018, the share of electrified municipal fleets is below $0.1 \%$. Of course, it is too early to see results of more recent activities such as the "Immediate Programme of Clean Air". However, it seems unlikely that a greater effect on stock numbers of electric vehicles will be detected.

Even taking all aspects (data availability and definition of municipal fleets) into account, there is a slight uptake of the share of municipal fleets of the total vehicle stock, although the electrification of municipal fleets has not much advanced in Germany until today. 


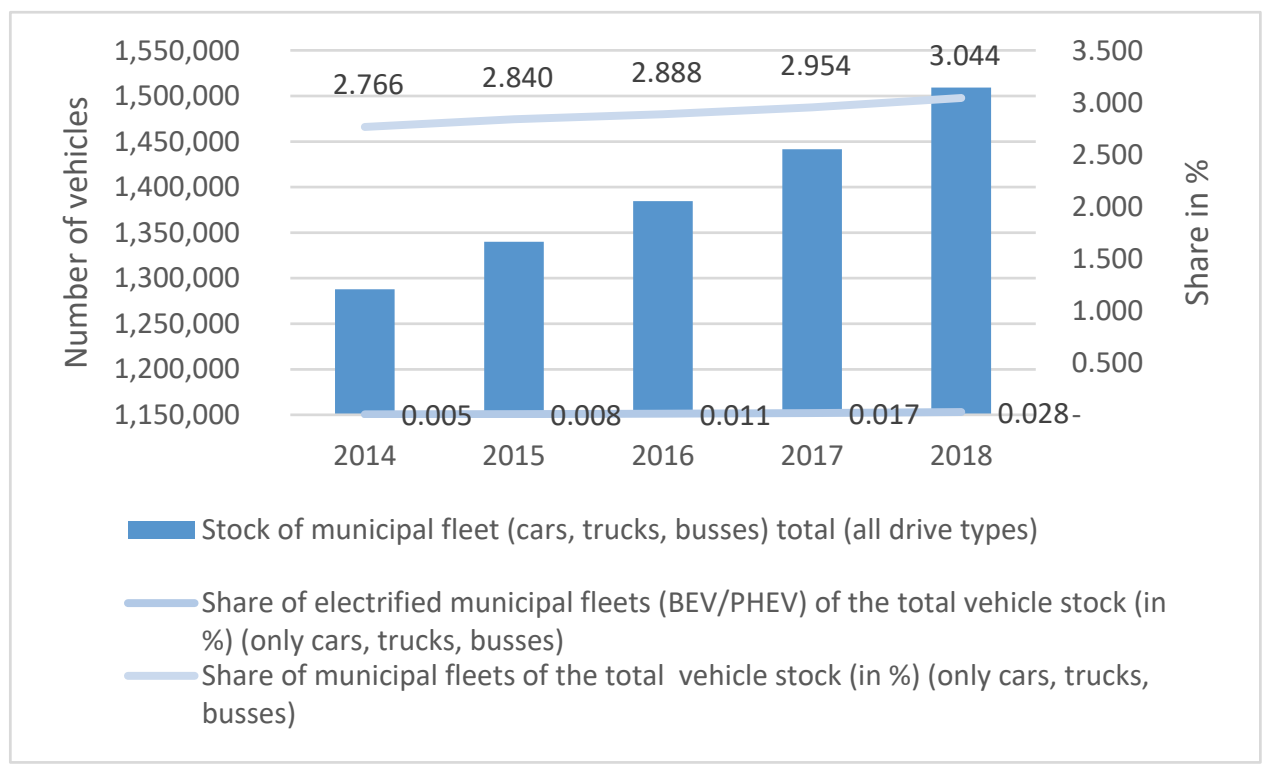

Figure 5. Growth of electrified municipal fleets (cars, trucks, buses, all drive types). (Source: own diagram; Data Source: [21], the year given is the year of reporting).

3.3. Focus on Low-Emission Buses and Flexible Services-A Closer Look at the Action Field Public Transport in the GCPS

Improving public transport is a priority for around $70 \%$ of all cities, as illustrated in Figure 6. While some cities with less than $100 \mathrm{k}$ or more than $500 \mathrm{k}$ inhabitants do not plan measures in this field, almost all cities with $100 \mathrm{k}$ to $500 \mathrm{k}$ inhabitants plan corresponding measures.

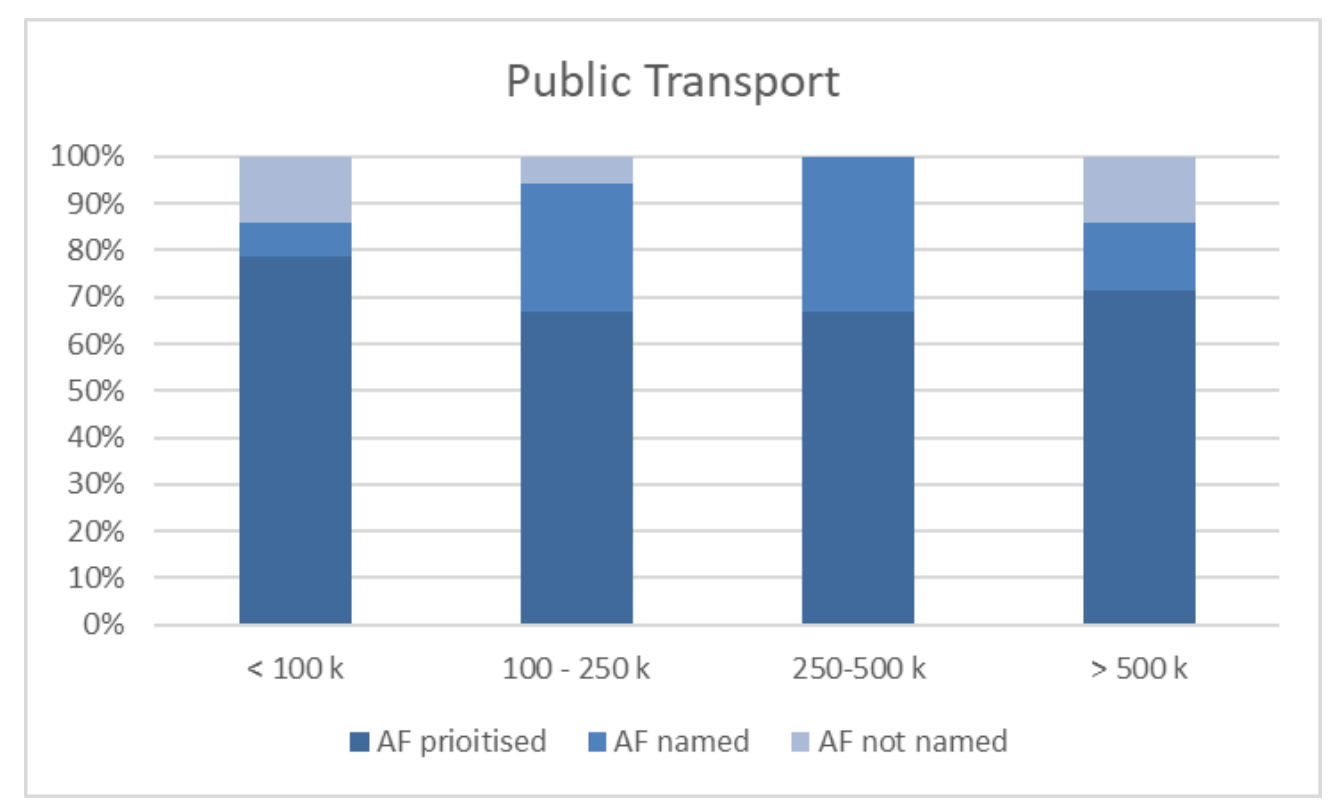

Figure 6. Action Field (AF) Public Transport. A differentiation is made as to whether measures are prioritized, mentioned at all, or not mentioned. Total number of analyzed Green City Plans: 55.

The focus in this field of action is on the conversion of diesel buses to low-emission buses by gas, hydrogen, hybrids or locally emission-free drives by electric buses as well as on upgrading the infrastructure and expanding the offering. The second priority is to improve the quality and quantity of PT. The cities are planning to expand their PT systems, especially on the outskirts and during off-peak hours by introducing ride-sharing, ride-heeling, or shuttle buses. 


\subsection{Charging Infrastructure for Battery Electric Buses}

In some European cities, such as Eindhoven, London, Oslo, Hamburg, or Hannover, battery-electric buses entered public transport fleets. Some cities even proclaim to install fully emission-free bus fleets by 2030 or 2050. Nevertheless, barriers especially regarding charging infrastructures, need to be overcome.

The installation of the charging infrastructure highly depends on the local framework conditions, such as schedules and routes of the bus lanes, line characteristics, conditions at the depots and stopping spaces as well as topography, weather, traffic, transported passengers, etc. Therefore, a detailed analysis of influencing factors needs to be executed in the first place. Based on this, a charging concept including charging strategies has to be elaborated. It is not given that the current diesel-based bus operation system could be transformed into an electric system without any modification. It could be helpful to customize routing of the bus lines, schedules, or bus sizes, for example [22].

At present, two main conductive charging strategies for battery electric buses are market-ready: Depot charging (power rates up to $150 \mathrm{~kW}$ ) and opportunity charging (power rates between 200 and $450 \mathrm{~kW}$ ), using a connector or pantograph. These solutions can also be operated via automated contact systems. Inductive or wireless charging solutions are operated in pilot projects as well. In this article, only depot charging will be discussed [22].

The interoperability of the charging infrastructure is still an unsolved issue. To date, there has been no standardization of the communication between vehicle and charging infrastructure or standardized contact systems. A mandate for the standardization for charging of buses was published by the European Commission to finalize standardization by the end of 2019. This process is not yet finished. Furthermore, bus depot grid connections usually are not designed for high electricity power loads. To facilitate for the bus depots the high electricity power loads, additional transformers have to be installed or the bus depot needs to be connected directly to a medium-voltage power grid. However, these connections are often limited to max. 4 MW. As local situations highly differ, grid loads have to be calculated individually [22].

London's Waterloo bus depot supplies 46 electric buses with power and is a good practice example for the realization of a fully electrified bus depot. In 2016, a grid connection of $2.5 \mathrm{MW}$ and two new substations with $11 \mathrm{kV}$ with two transformers, which reduce the power to $410 \mathrm{~V}$, were installed [23,24]. In total, the bus depot provides 40 smart-charging points with $40 \mathrm{~kW}$ charging power. Construction time was six months. The success of this example is based on close cooperation between the public transport operator, the municipality and the energy supplier.

Accordingly, a detailed charging strategy needs to be elaborated to electrify a bus fleet. The main issues will be the local framework conditions regarding grid connection respectively grid limitations, charging power load, standardisation on infrastructure, and infrastructure communication.

\subsection{Mobility Concepts Playing a Minor and Complementary Role—A Closer Look on the Action Field Mobility Concepts in the GCPS}

Nearly $80 \%$ of the German cities mention innovative mobility concepts in their GCPs, as shown in Figure 7. Basically, mobility concepts play a minor and mainly complementary role in most GCPs. Mobility concepts are seen as a supportive part of the transport system mainly by smaller and medium-sized cities.

Most of the cities revive the idea of multimodal hubs (German wording: "mobility station") and Park and Ride Stations (P\&R). P\&R infrastructure should be expanded spatially regarding the amount of opportunities to switch between individual to collective transport modes. P\&R systems should also be developed regarding the amount of transport modes that should be connected as well as supported by digital information systems. Quite often, installations of charging infrastructure for electric cars and e-bikes are mentioned as well as the offer of bike-sharing systems. The same development could be seen for multimodal hubs, which mainly should connect PT with sharing systems, collective on-demand services, and cycling. 


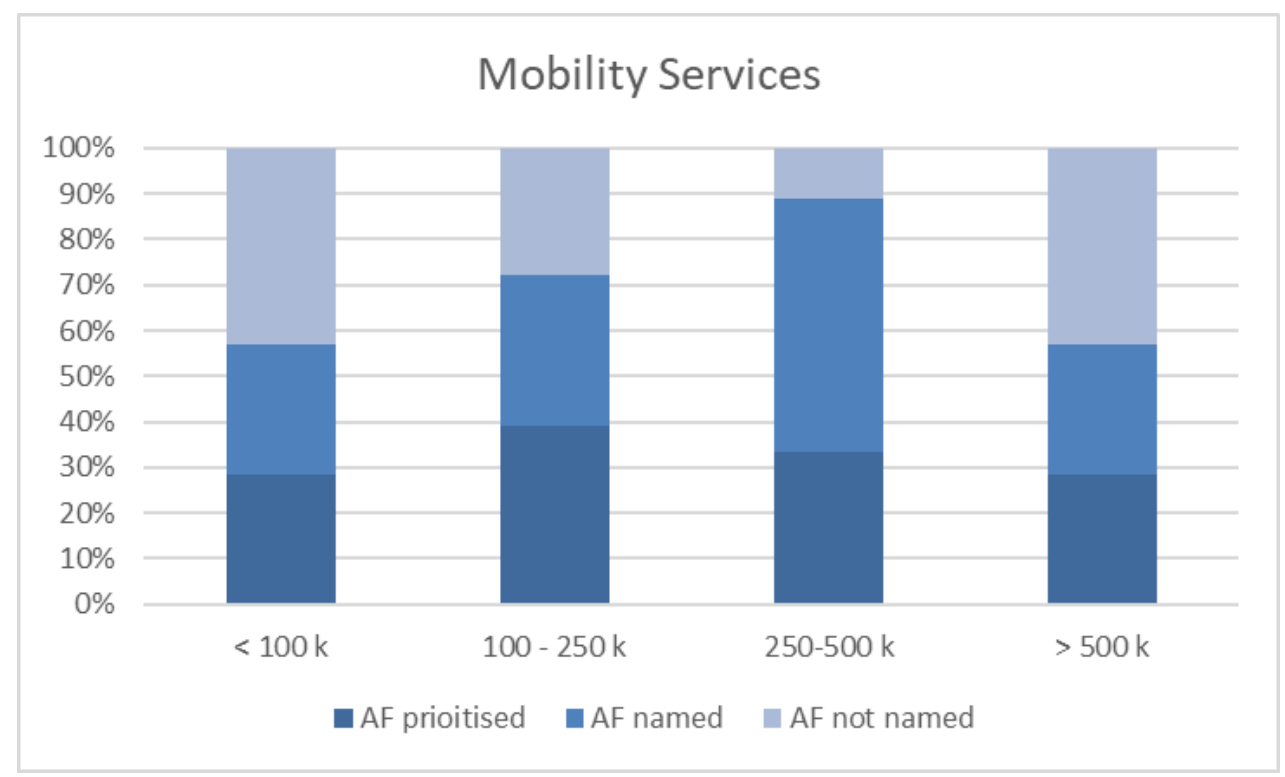

Figure 7. Action field (AF) mobility concepts. A differentiation is made as to whether measures are prioritized, mentioned at all, or not mentioned. Total number of analyzed Green City Plans: 55.

The implementation of Mobility as a Service (MaaS) and digital multimodal platforms is currently under discussion in Germany. Within the GCPs these concepts are rarely mentioned, mainly by cities where such services already exist, which will be further developed and brought to a new level. For example, in Aachen, an online service called "mobility broker" is intended to provide operational vehicle sharing and a cost-sharing model for electric mobility.

Many cities stated the aim to reduce car ownership by offering smart car-sharing systems. In most of the German cities, different kinds of car-sharing services can be found. Thus, existing car-sharing systems will mainly be digitally and spatially connected to other modes, expanded and electrified. Only a few cities state the aim to build up a new car-sharing system. These city approaches on sharing concepts culminate in common vehicle fleets for municipal use as well as mobility management for municipalities and public institutions.

To supplement public transport in off-peak times and peripheral areas, many cities plan to install on-demand services. These mainly concern collective ride-sharing systems or ride-hailing systems. Often these services should be provided with electric vehicles.

Autonomous vehicles are part of a future mobility vision and substantiated planning. This technology, as well as related potential services, is rarely discussed in the GCPs. Only very few cities mentioned autonomous shuttles.

From the analysis in this article, it is evident that cities and communities need tools to build visions for future mobility systems. Such a process has been implemented by the CSA Mobility4EU "Action Plan for the Future Mobility in Europe" [25]. While the project worked on all transport modes for urban and long-distance travels, important results have been derived, especially for regions, communities, and cities. On the one hand, a participatory creative tool for vision and action plan building, the story mapping method [26] has been combined with a scientific but equally participatory multi-actor multi-criteria analysis (MAMCA) [27]. Thereby, Mobility4EU had a clear focus on user perspectives and demands, the integration of modes as well as synergies and collaboration between modes and stakeholders. Furthermore, a European Transport and Mobility Forum [28] that continues the work beyond project duration and works on implementing the action plan has been initiated within the project.

The basis for the work on the vision was a study of user needs for transport. The analyzed user needs are rather complex but have been formulated on a higher level with as little overlap between 
each other as possible without losing important aspects by reducing complexity. They have been described as [26]:

1. End-users demand efficient and intelligently organized traffic and transport flows in all modes across borders and national networks.

2. While traveling, vehicle systems and services should be easy-to-use, comfortable and offer a flexible modal choice.

3. Opportunities for personalization of offers and to increase productivity and leisure time should be available.

4. There is an increasing demand for being informed in real time before and during traveling.

5. Users demand individually adaptable intermodal transport with fewer transfers and good last-mile services.

6. Inter-operability and reliability, as well as seamless end-to-end journeys, are key, but also inclusiveness, accessibility, and affordability of mobility offers.

7. Data security and privacy and, last but not least, safety in all traffic modes are of the highest importance to users.

8. Mobility should be low emission and low noise.

The MAMCA delivered two scenarios that have been ranked as preferable by the different stakeholder groups for transport of passenger and freight in all modes. Both scenarios emphasize the importance of policy and legal frameworks to enable an environment that is supportive of innovation and that fosters interoperability. The two scenarios are controversial regarding the importance of the individuality of lifestyles. They debate personalization and individualization vs. sharing, collective uses, and the importance of active mobility. While in the "Digital Nomads" capacity is built to fit demand, in the "Minimum Carbon" scenario efficient use of existing capacity and infrastructure is given more importance. In both scenarios, equity, data, and cybersecurity as well as strict regulation to foster innovation, interoperability and zero-emission mobility are called for. From these results, the vision was derived and describes a future of transport of passengers and freight that is decarbonized, sustainable in economic, environmental and social terms and offers tailored mobility solutions for all.

Consequent inclusion of the user in the entire innovation and development process will be imperative to achieve the goals of a sustainable and integrated transport system. At the same time, user-centric approaches have the potential also to act as a driver for the successful development and implementation of new technologies and services. For instance, universal design putting the user in the center delivers not only inclusive transport but improves mobility offers for all. To implement user-centric approaches, methodologies, tools as well as impact assessments have to be developed. This includes models for collaboration of users and the R\&D\&I community, the development of digital co-creation tools to enable broad collaborations, etc. Many examples of such can be found in [29].

The proliferation of new and especially of digital services needs planning on policy level for maximum impact benefitting all Europeans. Liability issues of automated systems and services, as well as new innovations, need to be tackled. Finally, solutions to create transport equity also in rural areas or urban areas with poorer inhabitants need to be strived for.

To achieve this, stakeholders from all modes and especially in the context of urban mobility-also from beyond the transport sector will have to outreach and collaborate with policymakers and also local and regional planners.

\section{Discussion: No System Change in German Cities Yet}

Electric mobility and traffic management are the focus areas of German Cities in the GCPs. Cities such as Leonberg, Freiburg, Stuttgart, Düsseldorf, and Paderborn could be highlighted as good practices due to supportive solutions such as smart grid integration of charging infrastructure, comprehensive infrastructure concepts and electric mobility contact points for the inhabitants [30]. 
Cycling and urban logistics are listed mainly in all GCPs, but both action fields are not particularly highlighted. The measures mentioned in these action fields are essentially the same in most of the GCPs and have been developed at a low level. To enhance cycling in the cities, basic measures such as the construction of cycling infrastructure (in some cities cycling highways), to strengthen the use of e-bikes and integrating cycling and cycling sharing systems into multimodal mobility hubs are necessary. It is the right step to make cycling more safe and faster. As the measures are rarely highlighted in the GCPs, we could not identify to what extent the infrastructure will be expanded compared to the other modes. The cities Hannover and Esslingen could be highlighted as best practice examples for cycling, the city of Heilbronn for a comprehensive footpath concept, the city Marburg for the innovative measure "green wave" for bicycles and Muenster for digital lightning on bicycle paths [30]. Overarching measures to reduce traffic problems caused by commercial transport are rarely to be found in the GCPs. At most, concepts as inner-city logistic hubs, shift to e-bikes and other lightweight electric vehicles on the last mile are mentioned but not specifically worked out. The cities of Bielefeld and Leipzig are best practice examples for innovative solutions for inner-city and micro logistic hubs, Hamburg for innovative solutions in the harbor [30].

Mobility concepts such as sharing, ride-hailing, multimodal services, platforms, etc. (prioritized and only mentioned) are becoming more important in the GCPs as the size of urban living spaces increases. However, this does not apply to cities with more than $500 \mathrm{k}$ inhabitants. Overall, the GCPs of cities with up to $500 \mathrm{k}$ inhabitants show relatively uniform focus on the same action fields. The plans of cities with more than $500 \mathrm{k}$ inhabitants are slightly heterogeneous. It gives the impression that the sets of measures and the prioritization are designed to be significantly more diverse than those in cities with a smaller population. Munich, Regensburg, Rhine-Neckar-Region came up with innovative mobility concepts in their GCPs [30].

Overall, the GCPs show an optimization of the actual situation, triggered by electrification and digitization. The electrification of municipal fleets, sharing fleets, and public transport buses is one of the measures with high priority within the GCPs. The electrification of public buses is approached by numerous cities even though the challenges are still quite extensive. The analyses of KBA data shows a slight uptake of the electrification of municipal fleets but no significant increase to date in Germany. There are numerous reasons for this slow development, e.g., for some purposes such as waste collection, only a few suitable vehicles are available on the market [9]. However, the electrification of municipal fleets might be a good way to promote electric mobility, for example, as a role model in a municipality. Considering the numbers, it is doubtful that fleet electrification could affect the market due to a non-existing scale-effect. Thus, focusing fleet electrification is not sufficient to promote electric mobility, and systemic aspects should be taken into account to succeed with the "Verkehrswende". More research on necessary systemic changes would provide clarification.

If cities acted decisively, environmental-friendly means of transport such as cycling, collective transport, and mobility services would be pursued much more consistently. In order to initiate real change, strong alternatives to motorized private transport and the consistent equality of all means of transport are necessary. Electrification and digitization are essential but equivalent components in the overall system without priority. It is a positive highlight that bus priority at traffic lights for a strong and fast PT is often mentioned in the GCPs. However, the overall picture of the GCPs does not show a consistent abandonment of car-oriented urban planning.

What do we learn from the German GCPs related to climate protection, environmentally friendly transport development and the mobility turnaround ("Verkehrswende")? The GCPs are very similar in their contents. The plans contain good approaches, which could be more elaborated regarding the interlinkage between the components of the transport system like PT, collective services, private cars, non-motorised modes. The GCPs should have addressed more of the determining criteria of modal choice, such as the ones Arcadis, included in the three pillars People, Planet, and Profit for the Sustainable Cities Mobility Index rating. The GCPs primarily optimize the status quo, disruptive or systemic measures to adjust the car-oriented urban planning are not envisaged. The system as 
a whole is not questioned in the GCPs. In order to initiate a sustainable change in transport, the measures formulated in the GCPs need to be supplemented by consistent restrictions on private motorized transport, requirements on commercial transport and allocate appropriate urban space to non-motorized, public, and collective transport. The scenario made in the CSA Mobility4EU emphasizes the importance of policy and legal frameworks to enable an environment that is supportive of innovation and that fosters interoperability, too. There are already first approaches in other countries, e.g., the bike-friendly city planning in the Netherlands or the Bonus Malus-System related to vehicle emissions in France. Considering the fact that only half of all German municipalities feel prepared for the challenges of digitization, whilst still being aware of the urgent need to implement new mobility concepts, they (especially small and medium-sized cities) need to be empowered to implement flexible and digital concepts and to establish a new systemic transport system. A consequent inclusion of the user in the development and planning process is needed to create a sustainable and integrated transport system. User-centric approaches also could be a driver for the implementation of new concepts. More research is needed on interdependencies between measures taken, user needs, new mobility concepts, impact assessment, potential pull and push factors for changing mindsets and ultimately behaviors as well as on user-centric approaches and methodologies.

Author Contributions: Conceptualization, D.J. and F.V.; methodology, D.J. and F.V.; formal analysis, D.J. and F.V.; Section 3.2, J.-H.G.; Section 3.4, A.R.; Section 3.5, B.M.; visualization, F.V.

Funding: The research on the GCPs received no external funding. However, Section 3.5 provides results from the EU funded project Mobility4EU project in the framework of the Horizon2020 program (EC Contract No. 690732).

Conflicts of Interest: The authors declare no conflict of interest.

\section{References}

1. Johnsen, D.; Vorholt, F. Electric Mobility and Smart Mobility Concepts-Restrained Uptake in German Cities. Presented at EVS32, Lyon, France, 19-22 May 2019.

2. German Bundestag. Current Climate Protection Goals at International, European and National Level; German Bundestag: Berlin, Germany, 2018.

3. Annual Mean $\mathrm{NO}_{2}$ Concentrations Observed at Traffic Stations. 2016. Available online: https: //www.eea.europa.eu/data-and-maps/figures/annual-mean-no2-concentration-observed-11 (accessed on 21 March 2019).

4. Bundesministerium der Justiz und für Verbraucherschutz. Gesetz zur Bevorrechtigung der Verwendung elektrisch betriebener Fahrzeuge (Elektromobilitätsgesetz-EmoG); Bundesministerium der Justiz und für Verbraucherschutz: Berlin, Germany, 2015.

5. Fraunhofer Institute for Systems and Innovation Research ISI. Electromobily in German Municipalities: City Survey 2017/2018; Interim Results; Fraunhofer Institute for Systems and Innovation Research ISI: Karlsruhe, Germany, 2018.

6. Competence Centre for Innovative Procurement (KOINNO). Innovative Public Procurement: Guideline, 2nd ed.; Federal Ministry for Economic Affairs and Energy (BMWi): Berlin, Germany, 2017.

7. Hornbostel, L.; Nerger, M.; Wittpahl, V.; Handschuh, A.; Salden, J. Zukunftsradar Digitale Kommune: Ergebnisbericht zur Umfrage 2019; Institute for Innovation and Technology (iit): Berlin, Germany, 2019.

8. VDI The Association of German Engineers. Municipal Survey of the Initiative City: Think: Commune Today and in the Year 2030; VDI The Association of German Engineers: Düsseldorf, Germany, 2017.

9. Elisabeth, D.; Uta, B.; Su-Min, C. Elektromobilität in Deutschen Kommunen: Eine Bestandsaufnahme; German Federal Ministry of Transport and Digital Infrastructure (BMVI): Berlin, Germany, 2019.

10. German Environment Agency (UBA). Elektromobilität Volkswirtschaftlich Klar im Vorteil: Ziele des Klimaschutzplans nur mit Energiewende im Verkehr zu Erreichen; German Environment Agency (UBA): Dessau-Roßlau, Germany, 2016.

11. Benevolo, C.; Dameri, R.; D'Auria, B. Smart Mobility in Smart City: Action Taxonomy, ICT Intensity and Public Benefits; Springer: Heidelberg, Germany, 2016. 
12. Monzon, A. Smart cities concept and chall: Bases for the assessment of smart city projects. In Proceedings of the 2015 International Conference on Smart Cities and Green ICT Systems (SMARTGREENS), Lisbon, Portugal, 20-22 May 2015.

13. Arcadis. Sustainable Cities Mobility Index 2017; Arcadis: Amsterdam, The Netherlands, 2017.

14. Biresselioǧlu, M.E.; Demirbag-Kaplan, M.; Yilmaz, B.K. Electric mobility in Europe: A comprehensive review of motivators and barriers in decision making processes. Transp. Res. Part A Policy Pract. 2018, 109, 1-13. [CrossRef]

15. Skrúcaný, T.; Kendra, M.; Stopka, O.; Milojević, S.T.; Figlus, T.; Csiszár, C. Impact of the electric mobility implementation on the greenhouse gases production in Central European countries. Sustainability 2019, 11, 4948. [CrossRef]

16. Lonza, L.; Moro, A. Electricity carbon intensity in European Member States: Impacts on GHG emissions of electric vehicles. Transp. Res. Part D Transp. Environ. 2018, 64, 5-14.

17. Plötz, P.; Gnann, T.; Sprei, F. Can policy measures foster plug-in electric vehicle market diffusion? World Electr. Veh. J. 2016, 8, 789-797. [CrossRef]

18. Harrison, G.; Thiel, C. An exploratory policy analysis of electric vehicle sales competition and sensitivity to infrastructure in Europe. Technol. Forecast. Soc. Chang. 2017, 114, 165-178. [CrossRef]

19. German Federal Ministry of Transport and Digital Infrastructure (BMVI). Masterplans Green City. Available online: https:/www.bmvi.de/DE/Themen/Mobilitaet/Sofortprogramm-Saubere-Luft/Masterplaene-GreenCity/masterplaene.html (accessed on 2 October 2019).

20. Aichinger, W.; Appelhans, N.; Gerlach, J.; Gies, J.; Hanke, S.; Klein-Hitpaß, A.; Warnecke, W. Elektromobilität in der Kommunalen Umsetzung: Kommunale Strategien und Planerische Instrumente; German Federal Ministry of Transport and Digital Infrastructure (BMVI): Berlin, Germany, 2015.

21. Kraftfahrt-Bundesamt-Statistik. Available online: www.kba.de/DE/Statistik/statistik_node.html (accessed on 10 October 2019).

22. Thoralf Knote, A.R. Deployment of Charging Infrastructure for Battery Electric Buses. In Towards User-Centric Transport in Europe 2: Enablers of Inclusive, Seamless and Sustainable Mobility; Springer: Berlin/Heidelberg, Germany, 2020; published soon.

23. Anonymous. Charging Station. Transport Engineer Magazin, 2018.

24. Baguette, S. Erstmals Betriebshof komplett auf Elektrobusse umgestellt. Magazin Nahverkehrs-Praxis, 3 August 2017.

25. Mobility4EU. CSA Mobility4EU “Action Plan for the future Mobility in Europe". Available online: www. mobility4eu.eu (accessed on 18 October 2019).

26. Bierau-Delpont, F.; Müller, B.; Napoletano, L.; Chalkia, E.; Meyer, G. Building an action plan for the holistic transformation of the European transport system. In Towards User-Centric Transport in Europe. Challenges, Solutions and Collaborations; Springer: Heidelberg, Germany, 2019.

27. Keseru, I.; Coosemans, T.; Macharis, C. Building scenarios for the future of transport in Europe: The Mobility4EU approach. In Towards User-Centric Transport in Europe; Springer: Heidelberg, Germany, 2019.

28. European Transport and Mobility Forum. Available online: https://www.mobility4eu.eu/ (accessed on 18 October 2019).

29. Müller, B.; Meyer, G. (Eds.) Towards User-Centric Transport in Europe 2: Enablers of Inclusive, Seamless and Sustainable Transport; Springer: Heidelberg, Germany, 2020; published soon.

30. German Federal Ministry of Transport and Digital Infrastructure (BMVI). Evaluation der 64 Kommunalen Green-City Pläne; Federal Ministry of Transport (BMVI): Berlin, Germany, 2018.

(C) 2019 by the authors. Licensee MDPI, Basel, Switzerland. This article is an open access article distributed under the terms and conditions of the Creative Commons Attribution (CC BY) license (http://creativecommons.org/licenses/by/4.0/). 